\title{
Familial Pituitary Adenomas: An Overview
}

\author{
Vladimir Vasilev, Adrian Daly, and Albert Beckers
}

\section{Contents}

Introduction.

Multiple Endocrine Neoplasia

Type 1 (Men 1)

Multiple Endocrine Neoplasia

Type 4 (Men 4).

106

Carney Complex 106

Familial Isolated Pituitary

Adenomas (FIPA)

Management of Familial

Pituitary Adenomas 109

References 110

\begin{abstract}
The recently recognized higher prevalence of pituitary tumours presents a challenge for endocrinologists and health-care resource providers in terms of diagnostics and therapy. The majority of pituitary tumors arise sporadically as anterior pituitary adenomas but approximately $5 \%$ can be attributed to a familial syndrome. The clinical and genetic characteristics of familial pituitary adenomas have been well portrayed in multiple endocrine neoplasia type 1 (MEN 1) and Carney complex (CNC). Recently, familial cases of pituitary tumours that were unrelated to MEN 1 or CNC were described under the clinical definition of familial isolated pituitary adenomas (FIPA). In $15-20 \%$ of FIPA patients, mutations in the AIP gene can be found. As clinical treatment in FIPA kindreds with AIP mutations and in MEN1 cases with pituitary adenomas can be challenging compared with sporadic cases, the issues of when and how best to screen subjects genetically, hormonally and radiologically have become increasingly prominent.
\end{abstract}

\section{Introduction}

Pituitary adenomas represent a diverse group of predominantly benign tumours whose comparatively high prevalence in general population continues to provoke significant interest among endocrinologists and neurosurgeons. According to the last report of the Primary Brain and Central
V. Vasilev•A. Daly • A. Beckers $(\bowtie)$

Department of Endocrinology, Centre Hospitalier Universitaire de Liege, Domaine Universitaire du Sart-Tilman, 4000 Liege, Belgium e-mail: albert.beckers@ chu.ulg.ac.be 
Brain Tumour Registry of the United States (2010) they are the third most common form of brain neoplasia comprising $12.7 \%$ of all brain tumours by histology type and the second most common entity (25.4\%) in young adults (20-34 years). Historically there has been a controversy concerning their prevalence in general population as autopsy and radiological series reported figures for incidentally-found pituitary adenomas as high as 14.4 and $22.5 \%$ respectively (Ezzat et al. 2004) while some older epidemiological studies estimated their prevalence rates as 19-28 cases per 100,000 inhabitants (Davis et al. 2001). Two recent community-based cross-sectional studies in the Belgian province of Liege (Daly et al. 2006b) and in Banbury, UK (Fernandez et al. 2010), however, suggest that clinically apparent pituitary adenomas may occur as frequently as 94 and 77.6 cases per 100,000 people respectively. These results indicate that the true prevalence of clinically relevant pituitary adenomas may have been underestimated previously.

The majority of pituitary adenomas occur sporadically and only 5\% arise in a familial setting; familial acromegaly has been described for well over a century (Erdheim 1903). Hereditary pituitary adenomas develop as a part of the distinct endocrine tumour syndromes: Multiple Endocrine Neoplasia type 1 (MEN1) and Carney Complex (CNC). The culprit gene in MEN1, MEN1, was identified in 1997 (Chandrasekharappa et al. 1997) and by 2008 approximately 565 different mutations were reported (Lemos and Thakker 2008). In 1985 Carney et al. (1986) described a new multiple tumour syndrome $(\mathrm{CNC})$ that presented infrequently with familial acromegaly. Genetic research has linked almost $70 \%$ of cases with Carney complex to mutations in the gene for type A regulatory subunit of protein kinase A (PRKAR1A) (Kirschner 2010). By the end of 1990s, however, significant numbers of patients had accumulated who had familial pituitary tumours without mutations in either MEN1 or PRKARIA genes. A new condition, termed Familial Isolated Pituitary Adenomas (FIPA) was coined to describe these families (Valdes Socin et al. 2000). Mutations in the aryl hydrocarbon receptor interacting protein $(A I P)$ gene were reported in FIPA patients (Vierimaa et al. 2006), but account for about 15-20\% of all patients with this disorder; therefore the search for other genetic causes is still ongoing.

\section{Multiple Endocrine Neoplasia Type 1 (Men 1)}

Multiple endocrine neoplasia type 1 (MEN 1) is a rare autosomal dominant condition with high penetrance and no sex predominance. It is characterized by the occurrence of primary hyperparathyroidism, enteropancreatic neuroendocrine tumours and pituitary adenomas; other associated non endocrine tumors can occur. Sporadic and familial forms have been described; the first presenting with pathology in at least two of the three principle endocrine glands and the second is defined as a MEN 1 case plus a first degree relative with one of these three tumours. Parathyroid adenomas are usually the first clinical manifestation of the disorder and affect as many as $95 \%$ of patients by the age of 50 (Falchetti et al. 2008). Diagnosed in $35-80 \%$ of patients, pancreatic islet cell tumours are the second most common presentation of MEN1 and are mostly characterized by excessive hormone production leading to marked clinical symptoms. Gastrinomas causing Zollinger-Ellison syndrome account for nearly a half of pancreatic lesions in MEN1 and due to multiple peptic ulcers and a large proportion of malignant tumours they represent one of the major causes for mortality and morbidity in this condition (Marini et al. 2006). The prevalence of pituitary tumours in MEN1 varies widely from 10 to $60 \%$ in the different studies and they are the first clinical manifestation of the disease in up to $25 \%$ of patients (Falchetti et al. 2008). However, only $2.7 \%$ of pituitary adenomas can be attributed to MEN 1 (Scheithauer et al. 1987). Pituitary pathology is much more prevalent in familial MEN 1 cases compared to non-familial ones. Also, women with MEN 1 have an increased predisposition to having a pituitary adenoma. Nearly all types of pituitary tumours have been reported, with prolactinomas being the most frequent, but the proportions of prolactin-secreting, 
$\mathrm{GH}$-secreting, ACTH-secreting and non-functional adenomas remain similar in MEN 1 cases and sporadic populations (Verges et al. 2002). Pituitary tumours in MEN 1, however, appear to be larger and more aggressive than their sporadic counterparts and macroadenomas comprise approximately $85 \%$ of them compared to only $42 \%$ of non-MEN 1 pituitary adenomas. This is probably one of the reasons why MEN 1 pituitary tumours are more likely to cause compression related symptoms. This tendency for aggressiveness is especially well observed in MEN 1 prolactinomas where the proportion of macroadenomas reaches $84 \%$ in contrast to the general population where microadenomas are the predominant prolactinoma phenotype (Daly et al. 2009). Response to therapy is also significantly lower in MEN 1 related pituitary tumours as only $42 \%$ of them achieve hormone normalization in contrast to sporadic functional pituitary adenomas where almost $90 \%$ of patients can be successfully treated (Verges et al. 2002). Apart from these three main types of neoplasms, over 20 other endocrine and non-endocrine tumours have been described in association with MEN 1. These include the less common carcinoid tumours and adrenal cortical tumours, usually non-secreting, as well as various inactive benign lesions such as lipomas, facial angiofibromas and collagenomas.

Genetic studies for loss of heterozigoty have linked the responsible gene to a locus on chromosome 11q13 (Larsson et al. 1988). The gene itself was cloned several years later (Chandrasekharappa et al. 1997) and consists of 10 exons, encoding a 610 amino acid protein, called menin. MEN1 is generally considered to act as a tumour suppressor gene and its transcript menin has been shown to interact with a variety of proteins that take part in transcriptional regulation, genome stability, cell proliferation and apoptosis. Localized predominantly in the nucleus, menin suppresses Jun- and NF- $\kappa \mathrm{B}$ mediated transcriptional activation, participates in the regulation of transforming growth factor- $\beta$ (TGF- $\beta$ ) signaling pathways by interacting with Smad family of proteins, regulates the expression of cyclin-dependant kinase inhibitors genes p27 and p18 by being a component in histone methyltransferase complexes, inhibits cell proliferation through interacting with the activator of S-phase kinase (ASK), maintains stable gene expression by controlling genome stability and DNA replication and repair (Lemos and Thakker 2008). Further more, numerous menin binding sites in chromatin were identified, many of them being not only within promoter regions, but also inside 3' end of genes as well as introns. However, none of the numerous menin functions has been proven critical in MEN1 tumorigenesis. A recent study demonstrated overexpression of transcriptional factor HLXB9 in pancreatic islet cells in the absence of menin (Scacheri et al. 2006), implicating the possibility that preferential targeting of specific genes by menin in endocrine tissue may explain the tendency for endocrine tumour formation. A pituitary specific function of menin is the interaction with activin - a negative regulator of prolactin, growth hormone and corticotropine secretion and pituitary cell proliferation, mediated through the inhibition of Pit-1 gene expression (Hendy et al. 2005).

Mutations in MEN1 gene are spread throughout the whole coding sequence and include $41 \%$ frameshift deletions, $23 \%$ nonsense mutations, $20 \%$ missense mutations, $9 \%$ splice-site mutations, $6 \%$ in-frame deletions and $1 \%$ whole gene deletions (Lemos and Thakker 2008). The majority of them lead to synthesis of truncated protein. The impact of the lack of menin on MEN 1 tumorigenesis has been studied in specially developed knockout mouse models. Homozigous animals $\left(\mathrm{MEN1}^{-/-}\right)$die early in embryonic phase with severe developmental defects in many organs while heterozygous mice $\left(\mathrm{MEN1}^{+/-}\right)$develop parathyroid adenomas and carcinomas, pancreatic islet cells tumours, pituitary adenomas and various other types of neoplasia, thus providing a model for human MEN 1 disease. Pituitary pathology in these animals is confined mainly to prolactinomas and somatotropinomas with a large proportion of malignant cases (Lemos and Thakker 2008).

So far no evident genotype-phenotype correlations have been observed although few kindreds with prevailing prolactinomas have been reported in Canada and Tasmania. Mutations in MEN1 are also detected in one third of sporadic enteropancreatic 
tumours and $20 \%$ of sporadic parathyroid adenomas but they seem to be extremely rare in sporadic pituitary adenomas although loss of heterozygoty in locus 11q13 has been proven for up to $30 \%$ of them (Daly et al. 2009).

\section{Multiple Endocrine Neoplasia Type 4 (Men 4)}

Despite the large number of identified mutations in coding regions of $M E N 1$ gene, DNA tests still fail to detect anomalies in more than $20 \%$ of patients with clinical characteristics of the disease. This may be due to mutations within introns or promoter regions or may also imply the involvement of other genes in the development of MEN 1-like conditions. Recently a mutation in $C D N K 1 B$ gene, coding cycline-dependant kinase inhibitor $\mathrm{p} 27^{\mathrm{Kip} 1}$, was identified in rats with MEN 1-like symptoms (Pellegata et al. 2006). The animals presented with numerous neuroendocrine tumours like pheochromocytoma, medullary thyroid carcinoma, parathyroid adenomas, pancreatic hyperplasia and pituitary adenomas. In humans $C D N K 1 B$ gene is located on chromosome 12p13 and its product $\mathrm{p} 27^{\mathrm{Kip} 1}$ plays an important role in cell cycle regulation by inhibiting cyclin/CDK complexes. Interestingly, pituitary adenomas originating from the intermediate lobe are the only tumours that develop spontaneously in homozygous $\mathrm{p} 27^{\mathrm{Kip} 1-/-}$ mice. Although mutations in human $C D K N 1 B$ gene are confirmed in only five families the condition was accepted as a new syndrome and called MEN 4. The first registered case was documented in a German kindred exhibiting familial acromegaly, primary hyperparathyroidism, renal angiomyolipoma and testicular cancer among various members. Genetic testing revealed a nonsense mutation in $C D K N 1 B$ gene in the absence of any detectable pathology in MEN1 gene (Pellegata et al. 2006). Soon after, a heterozygous germline frameshift mutation of $C D K N 1 B$ gene was reported in another MEN1like case, negative for MEN1 mutations, - a Dutch female patient with small-cell cervical carcinoma, ACTH-secreting pitui-tary adenoma and hyperparathyroidism. More recently, three novel mutations were identified in MEN1-like cases presenting with parathyroid and other endocrine tumours but without pituitary lesions (Agarwal et al. 2009). Mutations in CDKN1B gene are, however, found in less than $3 \%$ of patients with presumable MEN1 phenotypes, negative for MEN1 muatations, which suggests that other genetic factors may also be involved. (Pellegata et al. 2006; Agarwal et al. 2009).

\section{Carney Complex}

Carney Complex (CNC) is another autosomal dominant condition that is associated though infrequently with familial pituitary pathology, mainly acromegaly. The disease is characterized by spotty skin pigmentations, myxomas, endocrine hyperactivity and schwannomas and since the description of the first cohort of patients in 1985 (Carney et al. 1986) more than 500 patients have been reported in the largest database (Boikos and Stratakis 2007). Approximately $70 \%$ of cases with CNC present in a familial trait with slight female predominance. Benign skin lesions are the most common clinical manifestation of the disease and include lentigenes, cutaneous or mucosal myxomas, blue nevi and café-au-lait spots. Cardiac myxomas are the most frequent non-cutaneous lesions in $\mathrm{CNC}$ and account for more than a half of the diseasespecific mortality. Endocrine abnormalities are observed in approximately a third of CNC patients and are mainly due to Cushing's syndrome caused by primary pigmented nodular adrenocortical disease (PPNAD). Less common endocrine presentations include large cell calcifying sertoli cell tumours (LCCSCTs) and benign or malignant thyroid nodules (Boikos and Stratakis 2007). Pituitary adenomas occur with an incidence of $10-12 \%$ of CNC patients and usually cause acromegaly or gigantism depending on the age of onset but at least one family with prolactinomas has also been reported (Kirschner 2010). A distinguishing feature of $\mathrm{GH}$-secreting tumours in $\mathrm{CNC}$ is multifocal hyperplasia of somatomammotrope cells amidst normal pituitary tissue. This finding, together with 
the elevations in $\mathrm{GH}$ and $\mathrm{IGF}_{1}$ levels as well as mild hyperprolactinemia that can be detected in almost $75 \%$ of patients, suggests that acromegaly in CNC may develop insidiously from pituitary hyperplasia to overt adenoma.

Inactivating mutations in the gene for type $1 \mathrm{~A}$ regulatory subunit of protein kinase $\mathrm{A}$ (PRKAR1A), located on chromosome 17q22-24, have been identified in over $70 \%$ of patients with CNC. Unlike MEN 1, however, CNC is probably genetically heterogeneous as a second locus on chromosome $2 \mathrm{p} 16$ has been implicated although specific genetic alterations still have to be confirmed in affected families (Boikos and Stratakis 2007). As in MEN 1, no somatic mutations in PRKARIA gene have been documented in sporadic pituitary tumours. Protein kinase A (PKA) is a cAMP-dependant protein kinase composed of two regulatory and two catalytic subunits and is a component of a wide scope of metabolic and regulatory pathways involved in cell proliferation, transcription and apoptosis. The majority of PRKARIA gene mutations lead to premature stop codon generation and subsequent nonsense mRNA degradation. The loss of type $1 \mathrm{~A}$ regulatory subunits disrupts the balance in PKA tetramer formation and induces release of free catalytic subunits resulting in increased cAMP-dependant kinase activity in affected tissues (Robinson-White et al. 2006). In pituitary cells the stimulation of GHRH receptor by its ligand leads to $\mathrm{GH}$ synthesis and release through the PKA pathway and its specific activation in $\mathrm{CNC}$ may result in $\mathrm{GH}$ hypersecretion in the absence of physiologic signals. Complete knockout of PRKARIA gene in mice severely impairs cardiac morphogenesis and is lethal during early embryogenesis while heterozygous PRKARlA ${ }^{+/}$animals, despite exhibiting many of the tumour lesions observed in humans with $\mathrm{CNC}$, fail to develop any significant pituitary pathology. Tissue-specific ablation of PRKARIA gene in mice, however, induces gradual development of pituitary tumours with biochemical features, quite similar to CNC-related acromegaly in humans, e.g. GH hypersecretion with slow progression from hyperplasia to adenoma (Kirschner 2010).

\section{Familial Isolated Pituitary Adenomas (FIPA)}

Familial isolated pituitary adenomas (FIPA) represent a recently defined hereditary syndrome characterized by familial occurrence of pituitary tumours of any functional type in the absence of clinical and genetic features of MEN 1 and CNC (Beckers and Daly 2007). Since its first description at the end of the last century (Valdes Socin et al. 2000) active research and increased recognition has led to the identification of more than 200 families with this disorder (Chahal et al. 2010). However, FIPA is estimated to account only for $2.5 \%$ of all pituitary tumours, a proportion similar to MEN 1 (Daly et al. 2006a). Genealogical data from affected kindreds indicates autosomal dominant mode of inheritance with incomplete penetrance. Tumour phenotype within individual FIPA families may present in homogeneous manner with all affected members exhibiting the same adenoma type, or heterogeneously when different pituitary tumours arise within the kindred. All functional types of pituitary tumours may be associated with this condition but prolactin- or GH-secreting adenomas are almost inevitably present in affected families. Prolactin-secreting adenomas are the most common phenotype and comprise about $40 \%$ of all FIPA tumours Sexual predisposition, age of presentation and proportion of microadenomas are similar to sporadic prolactinomas. In heterogeneous FIPA families, however, they exhibit more aggressive behavior with significantly higher rates of suprasellar extension and cavernous sinus invasion. GH-secreting adenomas account for 30\% of FIPA tumours and somatoprolactinomas are responsible for another $7 \%$ of them. They are equally distributed between homogeneous and heterogeneous families but, unlike FIPA prolactinomas, somatotropinomas are more aggressive when occurring in a homogeneous setting. In homogeneous FIPA, acromegaly is usually diagnosed 10 years earlier with tumours more frequently displaying extracellar growth compared to heterogeneous kindreds and sporadic populations (Beckers and Daly 2007). Acromegaly in FIPA patients also appears to respond poorly to 
somatostatin analogue therapy (Leontiou et al. 2008). Non-secreting adenomas, predominantly associated with heterogeneous families, arise in $13 \%$ of FIPA patients and are also characterized by more aggressive evolution, being diagnosed earlier and exhibiting more invasive properties than sporadic adenomas. Gonadotropinomas, corticotropinomas and thyreotropinomas account for 4, 4 and 1\% of FIPA tumours respectively and are usually associated with other adenoma types in heterogeneous kindreds although individual families with homogeneous presentation have been reported (Beckers and Daly 2007).

In 2006 a detailed genome-wide screening in search for potential genes involved in familial adenoma tumorigenesis implicated that inactivating mutations in the gene coding aryl hydrocarbon receptor interacting protein $(A I P)$ could be responsible for familial acromegaly and prolactinomas in large Finnish kindreds (Vierimaa et al. 2006). Loss of heterozygoty at the AIP locus in tumour tissue from affected patients indicates that $A I P$ gene may experience a tumour suppressor function. In the largest cohorts of FIPA patients mutations in AIP gene can be found in approximately $22 \%$ of all cases and in $40 \%$ of families with acromegaly occurring in a homogeneous FIPA setting (Beckers and Daly, 2007; Chahal et al. 2010). Though quite infrequently, patients with sporadic pituitary tumours also seem to harbour AIP mutations with the majority of them having acromegaly. Within FIPA families, AIP mutation carriers are significantly younger at diagnosis and tend to have larger tumours than patients with normal AIP sequence (Daly et al. 2007). Contrary to the overall female predominance in FIPA, they are mostly men (71\%) and usually present with somatotropinomas or somatoprolactinomas (86\%) (Cazabat et al. 2009). There also exists some discrepancy in terms of clinical characteristics and histology results in tumours positive for AIP mutations as somatotropinomas are stained not only for GH but in a third of cases for prolactin and infrequently for FSH (Beckers and Daly 2007).

The AIP gene is ubiquitously expressed in various tissues throughout the body and in normal pituitary it is associated with secretory granules in somatotrope and lactotrope cells. In sporadic pituitary adenomas, however, $A I P$ is expressed in all tumour types but in prolacatinomas, nonsecreting adenomas and corticotropinomas it can only be identified in the cytoplasm whereas in somatotropinomas it is localized within secretory vesicles (Leontiou et al. 2008). The exact pathophysiological mechanisms that are involved in pituitary tumorigenesis caused by AIP mutations still remain unknown. Homozygous $A I P^{-/-}$ knockout mice develop severe cardiovascular abnormalities that are incompatible with life while heterozygotes $\left(\mathrm{AIP}^{+-}\right)$exhibit no pituitary pathology. The gene itself consists of 6 exons and encodes a 330 aminoacid protein which C-terminal end is required for binding to the aryl hydrocarbon receptor (AhR). This receptor acts as ligandinducible transcription factor and modulates cellular responses to various toxic environmental substances, such as dioxins (Beckers and Daly 2007). In the absence of ligands the AhR couples to a dimer of the $90 \mathrm{kDa}$ heat shock protein (HSP90), acting as chaperone, and AIP and p23 proteins, acting as co-chaperons, to form a multiprotein complex in the cytoplasm (Kazlauskas et al. 1999). The activation of the complex by its xenobiotic ligand results in nuclear translocation where AhR binds to the aryl hydrocarbon receptor nuclear translocator (ARNT) and promotes the transcription of specific genes coding various drug metabolizing enzymes as well as other proteins such as the cyclin dependant kinase inhibitor $\mathrm{p} 27^{\mathrm{Kip} 1}$. The role of AIP in the regulation of AhR activity is not quite clear, but it seems to participate in the stabilization and the cytoplasmic retention of the complex by an yet unknown mechanism. Data on the effect of AhR activation on cell proliferation are controversial but recently it was shown that reduced AIP expression in pituitary adenomas, positive for AIP mutations, is associated with decreased AhR activity, suggesting an inhibitory function of AhR in pituitary tumorigenesis (Jaffrain-Rea et al. 2009). Further more, AIP overexpression in cell cultures including pituitary cell lines slows down cell proliferation rates (Leontiou et al. 2008). Another possible pathophysiological link between AIP and pituitary tumorigenesis lies in the interaction with two specific types of phosphodiesterases - PDE4A5 
and PDE2A. These enzymes inactivate cyclic nucleotides like cAMP by disrupting the phosphodiester bond in their molecules and thus they may participate in the regulation of the various signaling pathways utilizing cAMP as intracellular second messenger, including the GHRH receptor cascade in pituitary cells. The interaction of AIP with PDE4A5, however, inhibits enzyme activity with resultant increase in cAMP concentration and it currently remains unclear if a tumour suppressor effect can be achieved in this way as cAMP overproduction is usually associated with pro-oncogenic outcomes. Binding to PDE2A interrupts the nuclear translocation of the AhR complex possibly by local reduction in cAMP levels (Ozfirat and Korbonits 2010). Very recently the tyrosine kinase receptor encoded by the RET protooncogene was identified as a novel binding partner of AIP in pituitary cells. Depending on the presence or the absence of its specific ligand - glial cell line-derived neurotropic factor (GDNF) RET promotes cell growth and migration or induces apoptosis respectively. More over, the domain responsible for the proapoptotic activity is the same that is responsible for AIP interaction. This RET-AIP binding presumably prevents the formation of a complex between AIP and survivin - a recently recognized apoptosis inhibitor and cell cycle regulator. Without the stabilizing role of AIP, survivin is put to rapid degradation with consequent increase in apoptosis (Vargiolu et al. 2009). In vitro studies, however, have failed to confirm that some missense AIP mutations could disrupt the association with RET (Chahal et al. 2010) and although it may be tempting to accept a more essential role of such interaction in pituitary tumorigenesis its true relevance remains questionable. Apart from stabilizing the AhR complex, AIP may also bind to a set of nuclear receptors including the peroxysome proliferatoractivated receptor $\alpha(\mathrm{PPAR} \alpha)$, the glucocorticoid receptor, and $\beta$-thyroid hormone receptor 1 (TR $\beta 1$ ). Further more, it has been proposed a role in virus induced tumorigenesis as a potential partner of hepatitis B virus $\mathrm{X}$ antigen and Epstein-Barr virusencoded nuclear antigen 3 (EBNA-3)(Ozfirat and Korbonits 2010). The outcomes of these interactions, however, still remain to be fully elucidated.
To date, more than 50 different mutations have been identified throughout the sequence of AIP gene and approximately $70 \%$ of them disrupt the C-terminal end of AIP polypeptide chain that is essential for protein-protein interactions. Nonsense and frameshift mutations lead to premature stop codons with resultant truncated protein while missense mutations tend to affect the TPR domains and the terminal $\alpha$-helix. Several mutations like R304, R271 and R81 are reported in independent FIPA families from different centers indicating possible mutational hotspots in the AIP gene while the Q14X mutation, though common in Finnish FIPA kindreds, has not been identified elsewhere suggesting possible founder effect (Ozfirat and Korbonits 2010). So far no genotype-phenotype correlations have been reported in FIPA families harbouring AIP mutations although some observations may imply a less aggressive character for mutations with conserved C-terminal part of AIP (Cazabat et al. 2009). Families with marked heredity for pituitary tumours, however, may lack mutations in AIP gene which is a strong indicator that other genetic disruptions may also be involved in FIPA development.

\section{Management of Familial Pituitary Adenomas}

Treatment of pituitary tumours that arise in familial setting practically does not differ from the management of sporadic adenomas in terms of indications and therapeutic approaches. Physicians should bear in mind, however, that pituitary tumours developing as a part of MEN 1 and FIPA syndromes have more aggressive evolution, present earlier and often respond poorly to therapy. As MEN 1 has been recognized for quite some time consensus statements and guidelines for the investigation and management of this condition have been developed (Brandi et al. 2001). Genetic testing for mutations in $M E N 1$ gene is warranted in patients who meet the clinical criteria for the disease and the identification of a mutation allows screening for carriers among the relatives. Mutation positive individuals should undergo annual biochemical assessment of prolactin, starting from the age of 5 , total serum calcium from 
the age of 8 and gastrin from age 20 as well as periodic (every 3-5 years) imaging tests to screen for relevant tumours. Mutation negative relatives can be surely excluded from further follow-up. When no mutation could be identified in the index case it may be appropriate to consider a haplotype or linkage analysis in an investigational laboratory provided sufficient number of affected family members is available. Testing for mutations in $C D K N 1 B$ gene in MEN 1-like cases without $M E N$ 1 mutations is still reserved only for research purposes as MEN 4 seems to be extremely rare condition. Similarly, patients meeting the diagnostic criteria for CNC should be tested for germline mutations in PRKARlA gene. Carriers should be followed-up for the different presentations of the syndrome and clinical, biochemical and imaging screening should be performed on a yearly basis. Regarding pituitary pathology, evaluation of $\mathrm{GH}$, $\mathrm{IGF}_{1}$ and prolactin secretion is appropriate. By definition FIPA is diagnosed in patients with hereditary pituitary tumours in the absence of mutations of MEN 1 and PRKARIA genes and as the number of reported families increase detailed family history is of essential importance in patients with pituitary adenomas. Although mutations of AIP gene are observed in only $20 \%$ of cases genetic testing in at least one affected member may be valuable from a clinical aspect as patients with mutations are associated with more aggressive disease. Identifying carriers among relatives is potentially beneficial for performing regular MRI and hormonal evaluation. In the absence of tumour on the imaging study surveillance may be carried on clinically and biochemically ( $\mathrm{IGF}_{1}$ and prolactin). Special attention should be paid to genetic counseling of FIPA patients and their relatives because of the relatively low prevalence of AIP mutations and the uncertain degree of penetrance. Genetic screening among sporadic pituitary adenomas may not be warranted in unselected cases but it may be considered in young patients with aggressive disease who are more likely to carry AIP mutations.

In conclusion, familial presentation of pituitary tumours although occurring in a small proportion of patients with pituitary adenoma provides a unique opportunity for investigation of genetic and molecular pathways of tumorigenesis.
In recent years the scope of familial pituitary syndromes has expanded with the definition of FIPA and MEN4 in addition to the well-described MEN1 and CNC. More over, modern technology has made possible not only the elucidation of culprit genetic defects behind these disorders but also presents an important tool for identifying at-risk individuals among affected families. The in-dept understanding of the specific evolution and clinical characteristics of familial syndromes may provide basis for preclinical diagnosis, better prevention and appropriate management of individual patients. Still, much remains to be done, especially in FIPA where the majority of patients do not harbour AIP mutations and may possibly have defects in yet unidentified genes. In addition, it is unclear whether FIPA patients have also predisposition for other endocrine or non-endocrine tumours which could expand its definition beyond the pituitary. Further clinical studies in larger populations as well as the development of appropriate experimental models may help elucidate these issues.

\section{References}

Agarwal SK, Mateo CM, Marx SJ (2009) Rare germline mutations in cyclin-dependent kinase inhibitor genes in multiple endocrine neoplasia type 1 and related states. J Clin Endocrinol Metab 94:1826-1834

Beckers A, Daly AF (2007) The clinical, pathological, and genetic features of familial isolated pituitary adenomas. Eur J Endocrinol 157:371-382

Boikos SA, Stratakis CA (2007) Carney complex: the first 20 years. Curr Opin Oncol 19:24-29

Brandi ML, Gagel RF, Angeli A, Bilezikian JP, BeckPeccoz P, Bordi C, Conte-Devolx B, Falchetti A, Gheri RG, Libroia A, Lips CJ, Lombardi G, Mannelli M, Pacini F, Ponder BA, Raue F, Skogseid B, Tamburrano G, Thakker RV, Thompson NW, Tomassetti P, Tonelli F, Wells SA Jr, Marx SJ (2001) Guidelines for diagnosis and therapy of MEN type 1 and type 2. J Clin Endocrinol Metab 86:5658-5671

Carney JA, Hruska LS, Beauchamp GD, Gordon H (1986) Dominant inheritance of the complex of myxomas, spotty pigmentation, and endocrine overactivity. Mayo Clin Proc 61:165-172

Cazabat L, Guillaud-Bataille M, Bertherat J, RaffinSanson ML (2009) Mutations of the gene for the aryl hydrocarbon receptor-interacting protein in pituitary adenomas. Horm Res 71:132-141

Chahal HS, Chapple JP, Frohman LA, Grossman AB, Korbonits M (2010) Clinical, genetic and molecular 
characterization of patients with familial isolated pituitary adenomas (FIPA). Trends Endocrinol Metab 21:419-427

Chandrasekharappa SC, Guru SC, Manickam P, Olufemi SE, Collins FS, Emmert-Buck MR, Debelenko LV, Zhuang Z, Lubensky IA, Liotta LA, Crabtree JS, Wang Y, Roe BA, Weisemann J, Boguski MS, Agarwal SK, Kester MB, Kim YS, Heppner C, Dong Q, Spiegel AM, Burns AL, Marx SJ (1997) Positional cloning of the gene for multiple endocrine neoplasia-type 1 . Science 276:404-407

Daly AF, Jaffrain-Rea ML, Ciccarelli A, Valdes-Socin H, Rohmer V, Tamburrano G, Borson-Chazot C, Estour B, Ciccarelli E, Brue T, Ferolla P, Emy P, Colao A, De Menis E, Lecomte P, Penfornis F, Delemer B, Bertherat J, Wemeau JL, De Herder W, Archambeaud F, Stevenaert A, Calender A, Murat A, Cavagnini F, Beckers A (2006a) Clinical characterization of familial isolated pituitary adenomas. J Clin Endocrinol Metab 91:3316-3323

Daly AF, Rixhon M, Adam C, Dempegioti A, Tichomirowa MA, Beckers A (2006b) High prevalence of pituitary adenomas: a cross-sectional study in the province of Liege, Belgium. J Clin Endocrinol Metab 91:4769-4775

Daly AF, Vanbellinghen JF, Khoo SK, Jaffrain-Rea ML, Naves LA, Guitelman MA, Murat A, Emy P, GimenezRoqueplo AP, Tamburrano G, Raverot G, Barlier A, De Herder W, Penfornis A, Ciccarelli E, Estour B, Lecomte P, Gatta B, Chabre O, Sabate MI, Bertagna X, Garcia Basavilbaso N, Stalldecker G, Colao A, Ferolla P, Wemeau JL, Caron P, Sadoul JL, Oneto A, Archambeaud F, Calender A, Sinilnikova O, Montanana CF, Cavagnini F, Hana V, Solano A, Delettieres D, Luccio-Camelo DC, Basso A, Rohmer V, Brue T, Bours V, Teh BT, Beckers A (2007) Aryl hydrocarbon receptor-interacting protein gene mutations in familial isolated pituitary adenomas: analysis in 73 families. J Clin Endocrinol Metab 92:1891-1896

Daly AF, Tichomirowa MA, Beckers A (2009) The epidemiology and genetics of pituitary adenomas. Best Pract Res Clin Endocrinol Metab 23:543-554

Davis JR, Farrell WE, Clayton RN (2001) Pituitary tumours. Reproduction 121:363-371

Dolecek TA, Propp JM, Stroup NE, Kruchko C. CBTRUS Statistical Report: Primary Brain and Central Nervous System Tumors Diagnosed in the United States in 2005-2009. Neuro-Oncol (2012) 14 (suppl 5): v1-v49.

Erdheim J (1903) Zur normalen und pathologischen Histologie der Glandula thyroidea, parathyroidea, und hypophysis. Beitr Pathol Anat 33:158-236

Ezzat S, Asa SL, Couldwell WT, Barr CE, Dodge WE, Vance ML, McCutcheon IE (2004) The prevalence of pituitary adenomas: a systematic review. Cancer 101:613-619

Falchetti A, Marini F, Luzi E, Tonelli F, Brandi ML (2008) Multiple endocrine neoplasms. Best Pract Res Clin Rheumatol 22:149-163

Fernandez A, Karavitaki N, Wass JA (2010) Prevalence of pituitary adenomas: a community-based, cross-sectional study in Banbury (Oxfordshire, UK). Clin Endocrinol (Oxf) 72:377-382
Hendy GN, Kaji H, Sowa H, Lebrun JJ, Canaff L (2005) Menin and TGF-beta superfamily member signaling via the Smad pathway in pituitary, parathyroid and osteoblast. Horm Metab Res 37:375-379

Jaffrain-Rea ML, Angelini M, Gargano D, Tichomirowa MA, Daly AF, Vanbellinghen JF, D'Innocenzo E, Barlier A, Giangaspero F, Esposito V, Ventura L, Arcella A, Theodoropoulou M, Naves LA, Fajardo C, Zacharieva S, Rohmer V, Brue T, Gulino A, Cantore G, Alesse E, Beckers A (2009) Expression of aryl hydrocarbon receptor (AHR) and AHR-interacting protein in pituitary adenomas: pathological and clinical implications. Endocr Relat Cancer 16:1029-1043

Kazlauskas A, Poellinger L, Pongratz I (1999) Evidence that the co-chaperone $\mathrm{p} 23$ regulates ligand responsiveness of the dioxin (Aryl hydrocarbon) receptor. J Biol Chem 274:13519-13524

Kirschner LS (2010) PRKAR1A and the evolution of pituitary tumors. Mol Cell Endocrinol 326(1-2):3-7

Larsson C, Skogseid B, Oberg K, Nakamura Y, Nordenskjold M (1988) Multiple endocrine neoplasia type 1 gene maps to chromosome 11 and is lost in insulinoma. Nature 332:85-87

Lemos MC, Thakker RV (2008) Multiple endocrine neoplasia type 1 (MEN1): analysis of 1336 mutations reported in the first decade following identification of the gene. Hum Mutat 29:22-32

Leontiou CA, Gueorguiev M, van der Spuy J, Quinton R, Lolli F, Hassan S, Chahal HS, Igreja SC, Jordan S, Rowe J, Stolbrink M, Christian HC, Wray J, BishopBailey D, Berney DM, Wass JA, Popovic V, RibeiroOliveira A Jr, Gadelha MR, Monson JP, Akker SA, Davis JR, Clayton RN, Yoshimoto K, Iwata T, Matsuno A, Eguchi K, Musat M, Flanagan D, Peters G, Bolger GB, Chapple JP, Frohman LA, Grossman AB, Korbonits M (2008) The role of the aryl hydrocarbon receptor-interacting protein gene in familial and sporadic pituitary adenomas. J Clin Endocrinol Metab 93:2390-2401

Marini F, Falchetti A, Del Monte F, Carbonell Sala S, Gozzini A, Luzi E, Brandi ML (2006) Multiple endocrine neoplasia type 1. Orphanet J Rare Dis 1:38

Ozfirat Z, Korbonits M (2010) AIP gene and familial isolated pituitary adenomas. Mol Cell Endocrinol 326 (1-2):71-79

Pellegata NS, Quintanilla-Martinez L, Siggelkow H, Samson E, Bink K, Hofler H, Fend F, Graw J, Atkinson MJ (2006) Germ-line mutations in p27Kip1 cause a multiple endocrine neoplasia syndrome in rats and humans. Proc Natl Acad Sci U S A 103:15558-15563

Robinson-White A, Meoli E, Stergiopoulos S, Horvath A, Boikos S, Bossis I, Stratakis CA (2006) PRKAR1A Mutations and protein kinase A interactions with other signaling pathways in the adrenal cortex. J Clin Endocrinol Metab 91:2380-2388

Scacheri PC, Davis S, Odom DT, Crawford GE, Perkins S, Halawi MJ, Agarwal SK, Marx SJ, Spiegel AM, Meltzer PS, Collins FS (2006) Genome-wide analysis 
of menin binding provides insights into MEN1 tumorigenesis. PLoS Genet 2:e51

Scheithauer BW, Laws ER Jr, Kovacs K, Horvath E, Randall RV, Carney JA (1987) Pituitary adenomas of the multiple endocrine neoplasia type I syndrome. Semin Diagn Pathol 4:205-211

Valdes Socin H, Poncin J, Stevens V, Stevenaert A, Beckers A (2000) Adenomes hypophysaires familiaux isoles non lies avec la mutation somatique NEM-1. Siuvi de 27 patients. Ann D Endocrinol 61:301

Vargiolu M, Fusco D, Kurelac I, Dirnberger D, Baumeister R, Morra I, Melcarne A, Rimondini R, Romeo G, Bonora E (2009) The tyrosine kinase receptor RET interacts in vivo with aryl hydrocarbon receptor- interacting protein to alter survivin availability. J Clin Endocrinol Metab 94:2571-2578

Verges B, Boureille F, Goudet P, Murat A, Beckers A, Sassolas G, Cougard P, Chambe B, Montvernay C, Calender A (2002) Pituitary disease in MEN type 1 (MEN1): data from the France-Belgium MEN1 multicenter study. J Clin Endocrinol Metab 87: 457-465

Vierimaa O, Georgitsi M, Lehtonen R, Vahteristo P, Kokko A, Raitila A, Tuppurainen K, Ebeling TM, Salmela PI, Paschke R, Gundogdu S, De Menis E, Makinen MJ, Launonen V, Karhu A, Aaltonen LA (2006) Pituitary adenoma predisposition caused by germline mutations in the AIP gene. Science 312:1228-1230 